\title{
The Social psychology of power (/review/10.5860/CHOICE.48-2379)
}

ed. by Ana Guinote and Theresa K. Vescio Guilford, 2010

469p, $9781606236192 \$ 60.00$

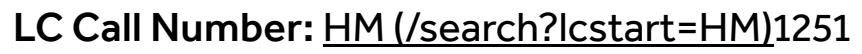

In their introduction, psychologists Guinote (Univ. College London, UK) and Vescio (Pennsylvania State Univ.) accurately describe this book as a comprehensive, much-needed update of research on the social psychology of power. The collection comprises 16 chapters organized in three relatively independent sections. The chapters in the first section look at the basic concepts, theoretical perspectives, and fundamental mechanisms that underlie the social psychology of power. A chapter by David Winter, in which he classifies the motivations underlying power, is particularly useful. Section 2 addresses a wide range--perhaps too wide--of notions of power in the context of social interaction, and section 3 focuses on power in intergroup relations, including the relationship of power to racism, sexism, and immigration. The writing style is academic--almost all of the authors are academic social psychologists--so the book is not one many will want to read word for word, beginning to end. But it is an excellent reference source for those seeking a comprehensive survey of the latest literature on the topic.

Summing Up: Recommended. Upper-division undergraduates through faculty and professionals.

Reviewer: R. Levine (/search?reviewer=R. Levine), California State University--Fresno

Recommendation: Recommended

Readership Level: Upper-division Undergraduates, Graduate Students, Researchers/Faculty Interdisciplinary Subjects:

Subject: Social \& Behavioral Sciences - Psychology (/search?q=\&sbj[]=psy)

Choice Issue: dec 2010 vol. 48 no. 4

Choice Review \#: 48-2379

Review DOI: 10.5860/CHOICE.48-2379 